\title{
Flavonoids and $\omega 3$-polyunsaturated fatty acid supplementation in renal transplant recipients: new arguments from COVID-19
}

\author{
Bruna Guida $^{1}$ (D) Maria Serena Lonardo ${ }^{1} \cdot$ Mauro Cataldi $^{2}$
}

Received: 30 July 2021 / Accepted: 21 October 2021 / Published online: 13 November 2021

(C) Italian Society of Nephrology 2021

Nutritional interventions are an important part of the standard treatment of kidney transplant recipients (KTRs) since they may prolong the life of the graft and ameliorate renal function. During the ongoing COVID-19 pandemic additional reasons emerged further reinforcing the relevance of a proper nutritional program in these patients. Being on chronic immunosuppressive therapy, KTRs are at higher risk than the general population of contracting COVID-19, which, like other infections in immunosuppressed patients, often has an aggressive clinical course with higher-thanaverage mortality [1]. In this context, the foods that are currently recommended to KTRs could be beneficial because they contain active compounds with antiviral, immunomodulating and anti-inflammatory properties. These general principles specifically apply to two classes of nutritional compounds: flavonoids and polyunsaturated fatty acids (PUFAs) (Table 1).

Flavonoids, which are responsible for most of the beneficial effects of fruits and vegetables, show antiviral, antioxidant, and anti-inflammatory activities in experimental models in vivo and in vitro. These immunomodulating and anti-inflammatory effects are supported by the inhibition of PI3K/Akt and of the inhibitor of kappa kinase/c-Jun aminoterminal kinases (IKK/JNK) with the consequent regulation of pro-inflammatory transcription factors, and, ultimately, the suppression of chemokines, COX-2, and cytokines. Interestingly, a direct inhibitory effect of flavonoids on COX-1 and COX-2 activity has also been demonstrated. In addition, in silico docking studies suggested that some flavonoids,

Bruna Guida

bguida@unina.it

1 Department of Clinical Medicine and Surgery, Physiology Nutrition Unit, Federico II University of Naples, Naples, Italy

2 Department of Neuroscience, Division of Pharmacology, Reproductive Sciences and Dentistry, Federico II University of Naples, Naples, Italy including naringenin, apigenin, luteolin and quercetin, may suppress SARS-CoV-2 cell penetration and/or replication by interacting with key viral or host proteins including the main viral protease, the RNA-dependent RNA polymerase, the spike protein $\mathrm{S}$ and its cellular receptor ACE-2 and the type 2 transmembrane serine protease, which is expressed on target cells and enhances viral entry through the cleavage and activation of the $\mathrm{S}$ protein. In addition, some of these flavonoids are active in vitro against other coronaviruses such as SARS-CoV (see [2] for review). Based on these data, the combined use of quercetin and vitamin $\mathrm{C}$ as a strategy for COVID-19 prevention and treatment has been suggested and two clinical trials have been completed (NCT04578158 and NCT04377789) while four are still ongoing to test the effect of quercetin in COVID-19 (NCT04861298, NCT04468139, NCT04851821, and NCT04853199) (see [3] for review).

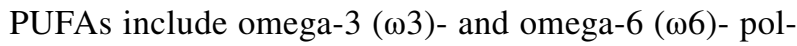
yunsaturated fatty acids such as eicosapentaenoic acid (EPA), docosahexaenoic acid (DHA), and alpha-linolenic acid (ALA) among the former, and arachidonic acid and its derivatives, the eicosanoids, among the latter. Since humans cannot produce $\omega 3$ - and $\omega 6$-PUFAs, these compounds must be taken with food. Fatty fish is the main source of EPA and DHA, while ALA is mainly found in vegetable oil and nuts. The intensity of inflammatory responses is finely adjusted through the balance between $\omega 3$ and $\omega 6$ PUFAs. In fact, while $\omega 6$ PUFAs are important mediators of inflammation, $\omega 3$-PUFAs play an anti-inflammatory role. Several mechanisms account for the anti-inflammatory activity of $\omega 3$-PUFAs, which inhibit the synthesis of $\omega 6$-derived proinflammatory eicosanoids (e.g., PGE2 and LTB4) and are converted into low potency metabolites, which compete with AA-derived mediators. In addition, $\omega 3$-PUFAs are converted into a newly discovered family of PUFA derivatives with anti inflammatory activity, the so-called pro-resolving lipid mediators, which include resolvins, derived from EPA (E-series) and DHA (D-series), and protectins and the maresins produced by DHA. Pro-resolving lipid mediators 
Table 1 Anti inflammatory and antiviral effects of flavonoids and PUFAs

\begin{tabular}{|c|c|c|}
\hline \multirow[t]{2}{*}{ Flavonoids } & Antinflammatory effects & $\begin{array}{l}\text {-Phospholipase A2 inhibition } \\
\text { - COX and LOX inhibition } \\
\text {-Decreased expression of COX and iNOS } \\
\text {-Inhibition of protein kinase C, MAP kinases and protein tyrosine kinases } \\
\text { - Reduced NFKB and AP-1 activation and cytokine gene transcription }\end{array}$ \\
\hline & Antiviral effects & $\begin{array}{l}\text {-Inhibition of the replication of influenza viruses, rotaviruses, HBV, HCV, Dengue virus } \\
\text {-Inhibition of HCV and RSV cellular entry } \\
\text {-HIV protease inhibition } \\
\text { - Reduced infectivity of human and bovine coronaviruses } \\
\text {-Inhibition of Porcine Epidemic Diarrhea coronavirus replication } \\
\text {-Inhibition of Sars-CoV and MERS proteases } \\
\text { - Binding to SARS-CoV N and SARS-CoV NTPase/helicase in vitro }\end{array}$ \\
\hline \multirow[t]{2}{*}{ PUFAs } & Antinflammatory effects & $\begin{array}{l}\text {-Decreased arachidonic acid metabolism and prostaglandin synthesis through the reduction of } \\
\text { COX expression and the competition for COX } \\
\text {-Decreased production of TNF- } \alpha, \text { IL-1 } \beta \text { and IL- } 6 \text { and increased production of IL-10 } \\
\text {-Decreased expression of adhesion molecules in endothelial cells, macrophages and lymphocytes } \\
\text {-Decreased IкB phosphorylation and NFKB activation in inflammatory cells in response to proin- } \\
\text { flammatory stimuli }\end{array}$ \\
\hline & Antiviral effects & $\begin{array}{l}\text {-Inhibition of HCV replication in vitro } \\
\text { - Decreased Japanese Encephalitis virus-induced neuroinflammation } \\
\text {-Inhibition by protectins of influenza virus replication } \\
\text { - Reduction by elovanoids of SARS-CoV-2 cell-entry in alveolar cells } \\
\text { - Reduction by endogenous PUFAs of the inflammatory response elicited by viral infection in mice } \\
\text { - Decreased IL-6 release in HIV and HHV-8 co-infected patients treated with PUFAs } \\
\text { - Correlation between } \omega-3 \text { plasma levels and prognosis in COVID-19 patients } \\
\text {-Improvement with PUFA supplementation of } 1 \text { month survival in severely ill COVID-19 patients }\end{array}$ \\
\hline
\end{tabular}

For further details on the data reported in the table the readers may refer to: Kim HP, Son KH, Chang HW, Kang SS (2004) Anti-inflammatory plant flavonoids and cellular action mechanisms. J Pharmacol Sci 96(3):229-245; Ninfali P, Antonelli A, Magnani M, Scarpa ES (2020) Antiviral properties of flavonoids and delivery strategies. Nutrients 12(9):2534; Calder PC (2017) Omega-3 fatty acids and inflammatory processes: from molecules to man. Biochem Soc Trans 45(5):1105-1115; Hathaway D, Pandav K, Patel M, Riva-Moscoso A, Singh BM, Patel A, Min ZC, Singh-Makkar S, Sana MK, Sanchez-Dopazo R, Desir R, Fahem MMM, Manella S, Rodriguez I, Alvarez A, Abreu R (2020) Omega 3 fatty acids and COVID-19: a comprehensive review. Infect Chemother 52(4):478-495

not only exert anti-inflammatory effects but also play a role in resolving inflammation. Since $\omega 3$ - and $\omega 6$-PUFAs compete for the same enzymes, and, as mentioned above, they cannot be synthesized endogenously, their relative abundance in food will determine whether pro- or anti-inflammatory effects predominate. Importantly, glucocorticoids that are taken as part of the standard anti-rejection therapy decrease the activity of $\Delta 5$ and $\Delta 6$ desaturates, the key enzymes for the conversion of ALA into EPA and DHA and, therefore they decrease the levels of these lipid derivatives. Fish and other seafood are rich in the $\omega 3$-PUFAs EPA and DHA and may represent an appropriate nutritional source of these compounds in KTRs. We have recently shown that, in KTRs, a $\omega 3$-PUFA-rich diet consisting of these foods lowers inflammation biomarkers including IL-6, CRP and ferritin [4]. Interestingly, it has been proposed that because of their ability to prevent and resolve inflammation, $\omega 3$-PUFAs could be beneficial in COVID-19 by reducing the severity of lung inflammation and the risk of developing the "cytokine storm syndrome" [5].

In conclusion, although clinical evidence is still limited, it appears plausible that good nutritional care may help KTRs cope with COVID-19. In this perspective, COVID-19 adds new arguments to suggest that proper nutritional interventions, though often underestimated and included only in few guidelines, have a crucial role in in the management of KRTs.

\section{Compliance with ethical standards}

Conflict of interest The authors have no conflict of interest to disclose.

Ethical approval Ethical approval is not required for review studies not including novel data as the present commentary.

\section{References}

1. Bell S, Campbell J, McDonald J, O’Neill M, Watters C, Buck K, Cousland Z, Findlay M, Lone NI, Metcalfe W, Methven S, Peel R, Almond A, Sanu V, Spalding E, Thomson PC, Mark PB, Traynor JP, Registry SR (2020) COVID-19 in patients undergoing chronic kidney replacement therapy and kidney transplant recipients in Scotland: findings and experience from the Scottish renal registry. BMC Nephrol 21:419 
2. Alzaabi MM, Hamdy R, Ashmawy NS, Hamoda AM, Alkhayat F, Khademi NN, Al Joud SMA, El-Keblawy AA, Soliman SSM (2021) Flavonoids are promising safe therapy against COVID-19. Phytochem Rev 22:1-22

3. Di Matteo G, Spano M, Grosso M, Salvo A, Ingallina C, Russo M, Ritieni A, Mannina L (2020) Food and COVID-19: preventive/ co-therapeutic strategies explored by current clinical trials and in silico studies. Foods 9:1036

4. Sabbatini M, Apicella L, Cataldi M, Maresca I, Nastasi A, Vitale S, Memoli B, Postiglione L, Riccio E, Gallo R, Federico S, Guida B (2013) Effects of a diet rich in N-3 polyunsaturated fatty acids on systemic inflammation in renal transplant recipients. J Am Coll Nutr 32:375-383
5. Weill P, Plissonneau C, Legrand P, Rioux V, Thibault R (2020) May omega-3 fatty acid dietary supplementation help reduce severe complications in Covid-19 patients? Biochimie 179:275-280

Publisher's Note Springer Nature remains neutral with regard to jurisdictional claims in published maps and institutional affiliations. 